\title{
ADSORPTION STUDIES ON REACTIVE YELLOW-14 DYE USING THE LEAVES OF Averrhoa bilimbi
}

\author{
H. Revathi ${ }^{1 *}$, Ashlin Xavier1, M. Dinesh Kumar ${ }^{1}$, T.Saranya1 \\ A. Kaviyarasu' ${ }^{1}$ and T.Murugan ${ }^{2}$ \\ ${ }^{1}$ Department of Chemistry, Karpagam Academy of Higher Education, \\ Coimbatore 641 021, India \\ ${ }^{2}$ Department of Chemistry, Adithya Institute of Technology, Coimbatore-641 107, India \\ *E-mail: catchreva@gmail.com
}

\begin{abstract}
The adsorbent prepared from Averrhoa bilimbi was used to remove Reactive Yellow-14 dye from wastewater by adsorption. Various parameters like Biomass dose, Equilibration time, $\mathrm{pH}$ were studied. The adsorption isotherms have been analyzed and fitted with the Freundlich model. Kinetic studies fit pseudo first order equation. It was concluded that the dye, Reactive Yellow-14 interacts well with an eco-friendly biomass-based adsorbent, the dried leaf powder of Averrhoa bilimbi.
\end{abstract}

Keywords: Reactive Yellow Dye-14, Averrhoa bilimbi, Adsorption Isotherms, Kinetics

(C) RASĀYAN. All rights reserved

\section{INTRODUCTION}

Applications of Reactive dyes around the globe are mostly used as cellulose fibers that possess main properties, such as having different brilliant shades of colors, soluble in water, affordable cost, the formation of a chemical covalent bond with the hydroxyl group of cellulose fibers, anionic and the color of the dyes shows fastness to washing ${ }^{1}$.Dyes are polymers, deeply colored and biodegradability is low in nature $^{2}$. In spite of high solubility in water, that is well beyond to the naturally occurring chromophoric groups (like azo, oxazine group, anthraquinone, formazane, metallized azo and phthalocyanine) and the bridging groups (like ether or ester covalent chemical bond) linkages are present between dyes and fibers. Reactive dyes find applications in the wool, cellulose and nylon, individually or as fiber blend compounds ${ }^{3}$.

Averrhoa bilimbi Linn. (Oxalidaceae, Common name: Bilimbi) is a common plant in Asia growing up to $15 \mathrm{~m}$ tall and $30 \mathrm{~cm}$ in diameter. Bilimbi is a nutritious fruit that grows mostly on the trunk of tall trees and it is a starchy fruit. Bilimbi is rich in Vitamin C. Not only vitamins and minerals the fruit also consists of ash, protein, moisture as well as fiber ${ }^{4}$.Literature survey about this plant shows that Averrhoa bilimbi is mainly used as a folk medicine in the treatment of diabetes mellitus, hypertension, and as an antimicrobial agent ${ }^{5}$. There are many reports on various aspects of fruits of Averrhoa bilimbi such as pharmacognostic studies, antimicrobial activity, antipuritic, antipyretic, antihelmintheticproperties ${ }^{6}$.

The bilimbi fruit was used in folk medicine to lower obesity in some southern parts of India. This gives an idea and led further studies on its antihyperlipidemic properties ${ }^{7}$.

Bilimbi leaves 3-6 cm long, are alternate and cluster at branch extremities. There are around 11 to 37 alternate or sub-opposite oblong leaflets ${ }^{8}$.In the Philippines, leaves are made into a paste and applied on skin eruptions, rheumatism, itches, mumps or swelling. They are also used for the bites of poisonous creatures.

Adsorption is a process where a solid is used for removing a soluble substance from the water and it is a cost-effective method for the removal of a pollutant from textile waste water due to the usage of low-cost adsorbent ${ }^{9}$.Activated carbon adsorption is a highly promising method ${ }^{10}$ for dye removal. But in the

Rasayan J. Chem., 12(2), 719-726(2019)

http://dx.doi.org/10.31788/RJC.2019.1225094

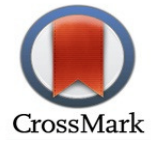


present study low-cost powdered dried leaves of Averrhoa bilimbiis used as an adsorbent to remove Reactive yellow-14 dye in aqueous solutions. Leaf biomass is a potential adsorbent for different dyes present in the wastewater of textile industries. Due to the porous structures of the leaves, they can adsorb dye molecules effectively ${ }^{11}$.

\section{EXPERIMENTAL}

ABLP leaves were collected from Kochi, Kerala. It was cleansed extensively with water to remove mud and foreign particle, crushed into small pieces and dehydrated under sunlight until the wetness gets dry out. It is then sieved to 400 microns. The ABLP was cleaned by washing with double distilled water till the washings show no color and no turbidity. The cleaned ABLP was evaporated under the sunlight and kept in airtight containers.

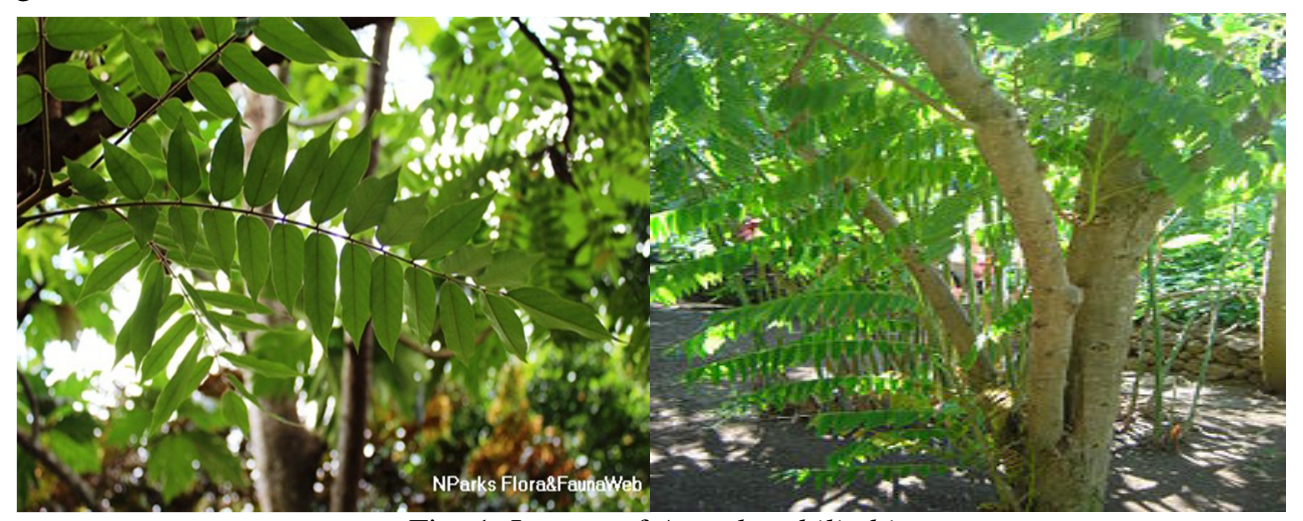

\section{Preparation of Stock Solution}

Fig.-1: Leaves of Averrhoa bilimbi

Dye RY-14 is universally used in the fabric industry, pulp industry etc ${ }^{1}$. The dye is anionic. The chemical formula of RY-14 dye is $\mathrm{C}_{20} \mathrm{H}_{19} \mathrm{ClN}_{4} \mathrm{Na}_{2} \mathrm{O}_{11} \mathrm{~S}_{3}$ and the molecular weight is $669 \mathrm{~g} / \mathrm{mol}$. 1 liter of distilled water was taken and $1 \mathrm{gm}$ of RY-14 was dissolved to prepare a bulk solution. The color of the solution was yellow. The experiment was performed by diluting the stock solution to our desired concentrations in $100 \mathrm{ml}$ of distilled water.

\section{Batch Experiment}

Adsorbent dosage, equilibration period, the effect of $\mathrm{pH}$ on the adsorption of dyes on ABLP was investigated by the adsorption experiments. The experiment was carried in $250 \mathrm{ml}$ stoppered reagent bottles with $100 \mathrm{ml}$ dye solution in a shaker at $200 \mathrm{rpm}$. The dye solution of resulting concentration was determined using UV- visible spectrophotometer at the wavelength of maximum absorption at $375 \mathrm{~nm}$ respectively. The effect of $\mathrm{pH}$ was studied over a $\mathrm{pH}$ range of 2 to $10.0 .1 \mathrm{~N} \mathrm{HCl}$ and $0.1 \mathrm{~N} \mathrm{NaOH}$ were used to adjust the $\mathrm{pH}$. The percentage $(\%)$ of dye removal was calculated using the equation:

$$
\text { Percentage of Dye Removal }(\%)=\left(\mathrm{C}_{\mathrm{i}^{-}} \mathrm{C}_{\mathrm{f}}\right) / \mathrm{C}_{\mathrm{i}} * 100
$$

Where,

$\mathrm{C}_{\mathrm{i}}$-Concentration of the Initial Dye

$\mathrm{C}_{\mathrm{f}}$-Concentration of the Final Dye

\section{Biomass Dosage}

\section{RESULTS AND DISCUSSION}

The adsorption of the dyes on raw material was studied by varying weight of the leaves of Averrhoa bilimbi biomass $(0.1-1.9 \mathrm{~g} / \mathrm{ml})$. The percentage of dye removal has been increased as the concentration of the adsorbent increases.

The maximum dye removal efficiency was observed at $1.9 \mathrm{~g}$ biomass of Averrhoa bilimbi dose containing $100 \mathrm{mg} / \mathrm{L}$ dye concentration.

\section{Effect of Equilibration Period}

Only a particular amount of adsorbate can be absorbed by an adsorbent. So the initial concentration is 
always important for an adsorbate solution. Amount of dye adsorbed versus time was plotted. The time variation plot indicates that the removal of dye has been increased with increase in time. At higher contact time, the rate of adsorption was found to be high. It was concluded a period of 240 minutes was necessary for the maximum percentage of dye removal by ABLP.

Table-1: Effect of Biomass Dose

\begin{tabular}{c|c|c}
\hline $\begin{array}{c}\text { S. } \\
\text { No. }\end{array}$ & $\begin{array}{c}\text { Weight of } \\
\text { Biomass }\end{array}$ & $\begin{array}{c}\text { \% of dye } \\
\text { removal }\end{array}$ \\
\hline 1 & 0.1 & 32.91 \\
\hline 2 & 0.3 & 45.38 \\
\hline 3 & 0.5 & 53.04 \\
\hline 4 & 0.7 & 56.15 \\
\hline 5 & 0.9 & 58.38 \\
\hline 6 & 1.1 & 59.33 \\
\hline 7 & 1.3 & 63.56 \\
\hline 8 & 1.5 & 73.47 \\
\hline 9 & 1.7 & 77.48 \\
\hline 10 & 1.9 & 82.68 \\
\hline
\end{tabular}

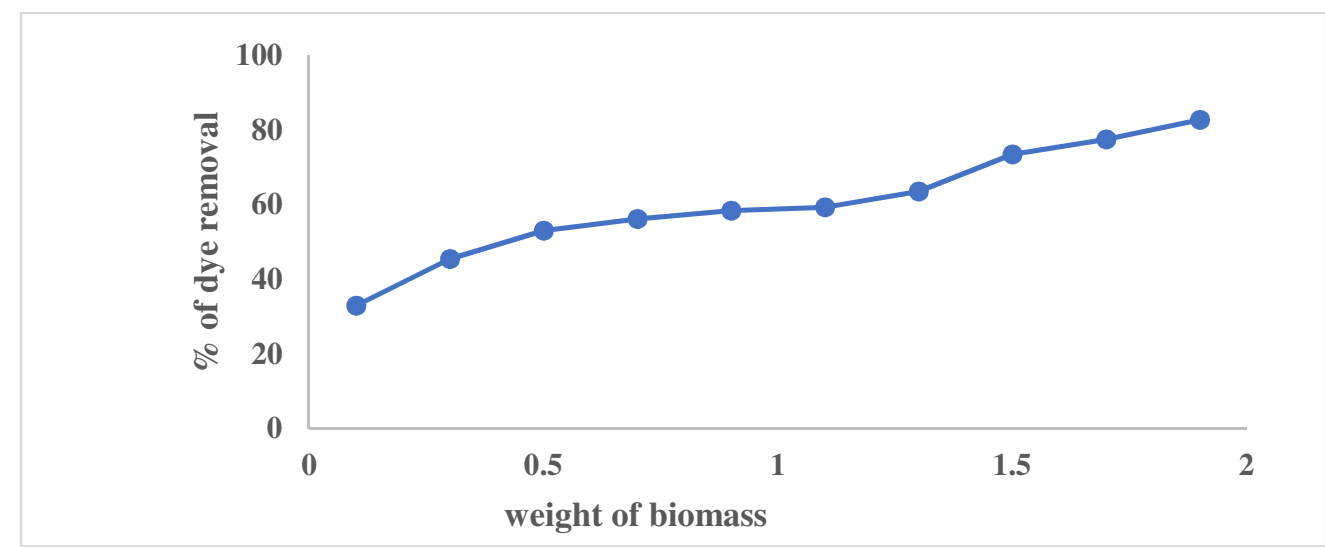

Fig.-2: Effect of Biomass on Biosorption of RY-14 Dye by the Biomass Averrhoa bilimbi

\begin{tabular}{c|c|c} 
Table-2: Effect of Equilibration Period \\
\hline S. No. & $\begin{array}{c}\text { Time } \\
\text { (min) }\end{array}$ & $\begin{array}{c}\text { \% of Dye } \\
\text { Removal }\end{array}$ \\
\hline 1 & 10 & 44.56 \\
\hline 2 & 20 & 48.19 \\
\hline 3 & 30 & 51.42 \\
\hline 4 & 60 & 54.98 \\
\hline 5 & 90 & 61.91 \\
\hline 6 & 120 & 65.58 \\
\hline 7 & 150 & 72.64 \\
\hline 8 & 180 & 76.92 \\
\hline 9 & 210 & 80.16 \\
\hline 10 & 240 & 84.19 \\
\hline
\end{tabular}

\section{Effect of $\mathbf{p H}$}

An important parameter in the adsorption process is $\mathrm{pH}$. The $\mathrm{pH}$ of an aqueous phase has a greater influence on the upper layer of the adsorbent molecules. $\mathrm{pH}$ of the medium controls the extent of electrostatic charges provided by the molecules of dyes. The experiment was performed by taking different $\mathrm{pH}$ values from 2 to 10 and its adsorption capacity on ABLP was scrutinized. Figure-4 shows the change in $\mathrm{pH}$ on the RY-14 dye adsorption on ABLP. 
The adsorption efficiency rapidly decreased as the $\mathrm{pH}$ of the dye solution increased. The Percentage removal of dye by ABLP was $80.64 \%$ at solution $\mathrm{pH}$ of 2 .Obtained results at optimum $\mathrm{pH}$ values of adsorbent were in good agreement with the values given in literature such as walnut shell, sawdust, clay, bentonite, native strains ${ }^{12}$.

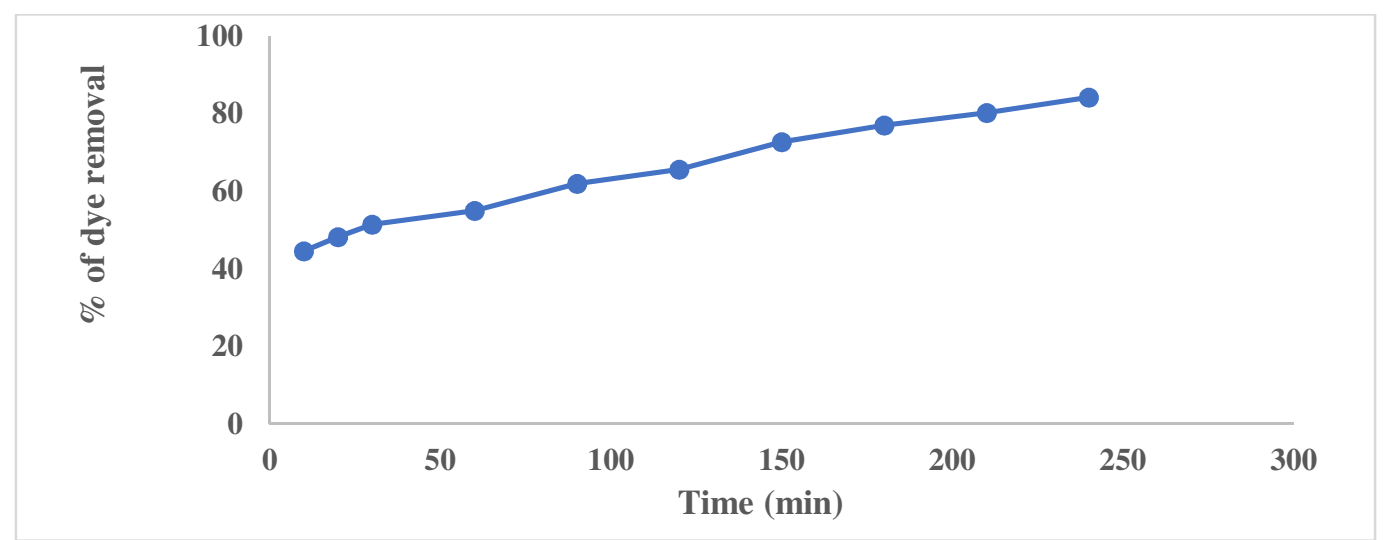

Fig.-3: Change in Equilibration Period on Sorption of Dye RY-14 by the Biomass Averrhoa bilimbi

At low $\mathrm{pH}$, percentage of dye removal was high and this is due to the electrostatic interaction between the positive surface charge of the adsorbent and the anionic dye.

When the $\mathrm{pH}$ of the solution was high there is always electrostatic repulsion takes place between the molecules of dye and the positively charged surface, decreasing percentage of removal of anionic dyes and the capacity of adsorption.

Table-3: Effect of $\mathrm{pH}$

\begin{tabular}{c|c|c}
\hline S. No. & $\mathrm{pH}$ & $\begin{array}{c}\text { \% of Dye } \\
\text { Removal }\end{array}$ \\
\hline 1 & 2 & 80.64 \\
\hline 2 & 3 & 74.45 \\
\hline 3 & 4 & 70.15 \\
\hline 4 & 5 & 66.23 \\
\hline 5 & 6 & 60.86 \\
\hline 6 & 7 & 55.47 \\
\hline 7 & 8 & 50.41 \\
\hline 8 & 9 & 45.92 \\
\hline 9 & 10 & 40.14 \\
\hline
\end{tabular}

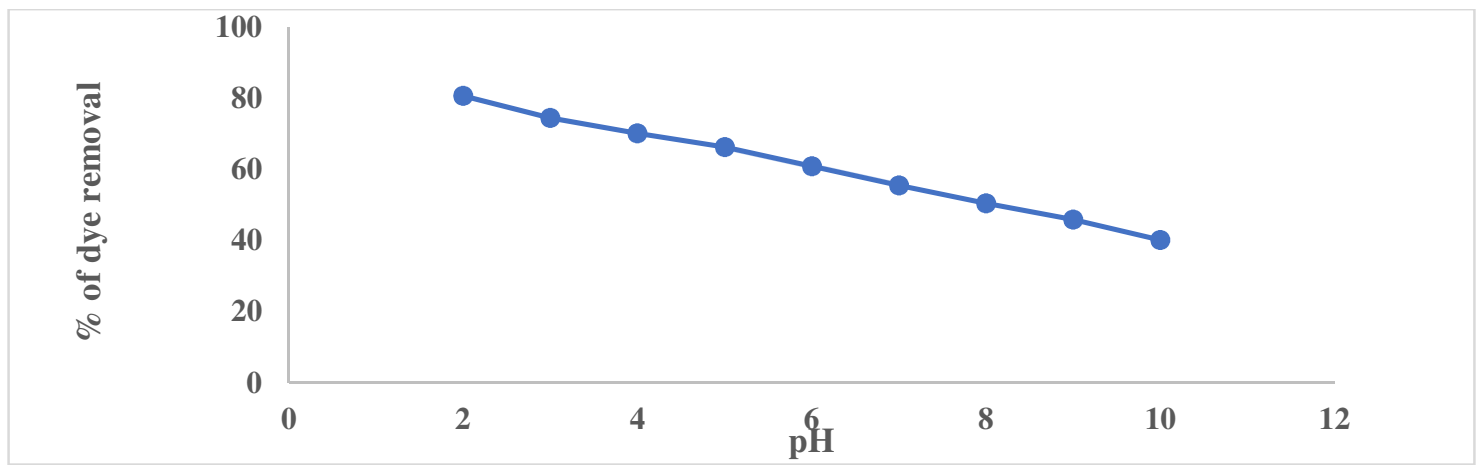

Fig.-4: Effect of $\mathrm{pH}$ of Dye RY-14 by the Biomass Averrhoa bilimbi

\section{Adsorption Isotherm}

The association between adsorbate and the adsorbent were well understood by the Isotherm studies ${ }^{13}$ and this study is further extended to explain the removal of pollutants from aqueous solutions. In the current 
research, the adsorption of reactive yellow-14 on ABLP showed that the rate of removal of RY-14 increases with an increase in dye concentrations and attains saturation at higher concentrations ${ }^{14}$. Isotherm models like Freundlich, Langmuir and Temkin were examined. Monolayer biosorption is well explained by Langmuir isotherm whereas biosorption onto a heterogeneous surface was well illustrated by Freundlich isotherm ${ }^{15}$.Correlation Coefficients of Freundlich, Langmuir and Temkin are tabulated in Table-4.

Table-4: $\mathrm{R}^{2}$ Values for Freudlich, Langmuir and Temkin Model
\begin{tabular}{c|c}
\hline Models & $\mathrm{R}^{2}$ \\
\hline Freundlich & 0.9196 \\
\hline Langmuir & 0.9108 \\
\hline Temkin & 0.8952 \\
\hline
\end{tabular}

\section{Freundlich Adsorption Isotherm}

Freundlich adsorption isotherm was checked. By using the graph the amount of dye adsorbed was calculated. Freundlich Isotherm model is used for multilayer adsorption between adsorbate and adsorbent ${ }^{16}$.

The heterogeneous biosorbing surface was explained by Freundlich and he further describes the vacant sites with distant energies ${ }^{17}$. The intensity of biosorption of a sorbent was given by this model. The empirical equation of this isotherm is:

$\log \mathrm{qe}=\log \mathrm{Kf}+1 / \mathrm{n} \log \mathrm{Ce}$

Where, Kf and $\mathrm{n}$ are constants with $\mathrm{n}$ indicating the biosorption process and $\mathrm{n}$ also indicates that the process is highly favorable, $\mathrm{Kf}\left((\mathrm{mg} / \mathrm{g})(\mathrm{L} / \mathrm{mg})^{1 / \mathrm{n}}\right.$ the biosorption capacity. Fig. -5 shows that the Freundlich isotherm was found to be linear and the correlation coefficient factor was found to be 0.9196. It was suggested that Freundlich Isotherm fits the experimental data and confirms the multilayer coverage on the adsorbent.

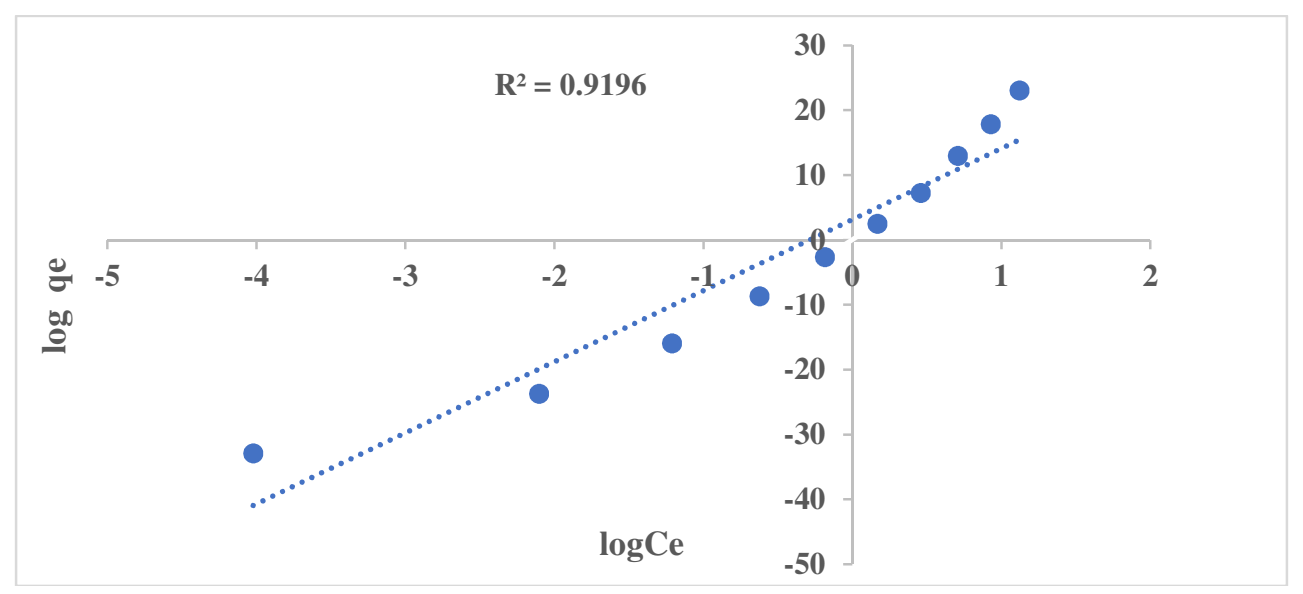

Fig.-5: Graph Showing log qe Vs log Ce

\section{Langmuir Adsorption Isotherm}

The Langmuir adsorption isotherm model suggests that adsorption occurs on homogeneous sites within an adsorbent based on the assumption that each molecule possesses constant enthalpies and sorption activation energy ${ }^{18}$. The equation is:

$\mathrm{C}_{\mathrm{e}} / \mathrm{q}_{\mathrm{e}}=1 / \mathrm{k}_{\mathrm{l}} \mathrm{q}_{\mathrm{m}}+1 / \mathrm{q}_{\mathrm{e}} \mathrm{Ce}$

Where Ce is a biosorbate concentration $(\mathrm{mg} / \mathrm{L})$, qe is the quantity of biosorbate adsorbed $(\mathrm{mg} / \mathrm{g}), \mathrm{k}_{1}$ and $\mathrm{q}_{\mathrm{m}}$ are constants of biosorption rate and capacity of biosorption. Langmuir isotherm was represented by plotting. In Ce with Ce/qe and slope of $1 / \mathrm{q}_{\mathrm{m}}$ was obtained. 
Langmuir model is achieved and this is proved by the linearity in the graph. The $\mathrm{R}^{2}$ value for RY-14 was obtained as 0.9108. It was found that $\mathrm{R}^{2}$ value of Langmuir isotherm was lower than Freundlich isotherm, which confirms the multilayer coverage of RY-14 onto ABLP.

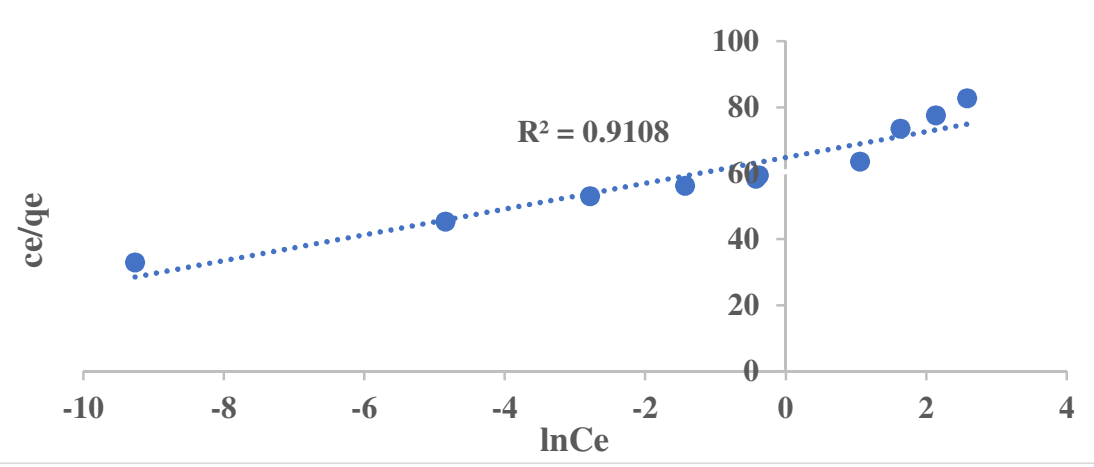

Fig.-6: Graph Showing $\mathrm{C}_{\mathrm{e}} / \mathrm{q}_{\mathrm{e}}$ Vs $\ln \mathrm{Ce}$

\section{Temkin Isotherm}

The equilibrium data was further applied to Temkin isotherm model. The Fig.-7 represents the linear plot of $\log \mathrm{Ce} \mathrm{Vs}$ qe of the Temkin isotherm.

It can be seen from the figure that $\mathrm{R}^{2}$ value for the adsorption was found to be 0.8952 which is comparatively lesser than other two models and shows that Temkin isotherm model was inapplicable.

The data of biosorption is analyzed as:

$\mathrm{q}_{\mathrm{e}}=\mathrm{B}_{\mathrm{T}} \log \left(\mathrm{A}_{\mathrm{T}}\right)+\mathrm{B}_{\mathrm{T}} \log \left(\mathrm{C}_{\mathrm{e}}\right)$

Where, $A_{T}$ and $B_{T}$ are the Temkin constants. $B_{T}=R T / b ; A_{T}=e\left(\right.$ intercept $\left./ B_{T}\right) ;(R=8.314 \mathrm{~J} / \mathrm{mol} \mathrm{K})$, $T$ is temperature represented in Kelvin.

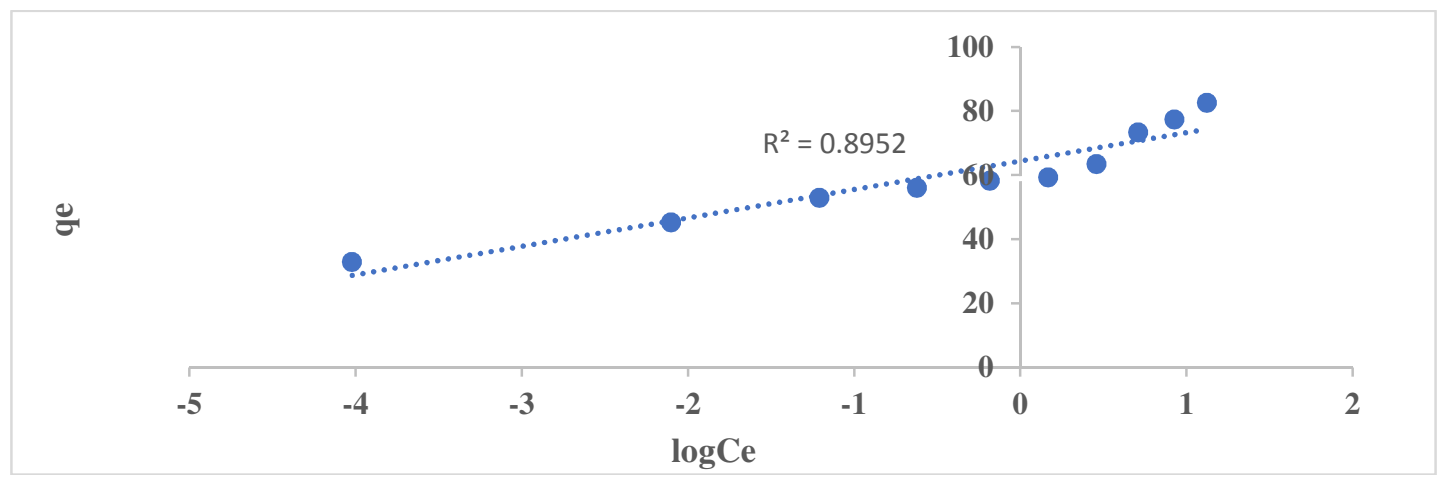

Fig.-7: Graph Showing qe Vs $\log \mathrm{Ce}$

\section{Kinetics of Adsorption}

The experimental data were tested with pseudo first order kinetic model.The kinetics of RY-14 adsorption on ABLP was studied with respect to different concentrations of dye solutions.

The rate constant is the plot of $\log 1-\mathrm{U}(\mathrm{t})$ Vs contact time and is shown in Fig.-9. The Kinetic equation of first order is given by:

$\ln (1-\mathrm{U}(\mathrm{t}))=-\mathrm{kt}$

$\mathrm{Ut}=\frac{C A-C A(t)}{C A-C A(e)}$

Where, $\mathrm{CA}=$ initial concentration $\mathrm{CA}(\mathrm{t})=$ concentration at time ' $\mathrm{t}$ ' and $\mathrm{CA}(\mathrm{e})=$ equilibrium dye concentrations for first order reaction. The slope indicates the rate constant $(\mathrm{K})$ of the reaction. First order kinetics is proved by the graph and a straight line was obtained.

\section{SEM Analysis}

Scanning Electron Microscopy studies were performed to characterize the surface morphology of the biomass before adsorption. Figure-10 shows the SEM image of ABLP before adsorption. ABLP has a 
considerable heterogeneous surface with a considerable number of cavities and more pores that can act as an excellent binding site for the dye adsorption ${ }^{19}$.

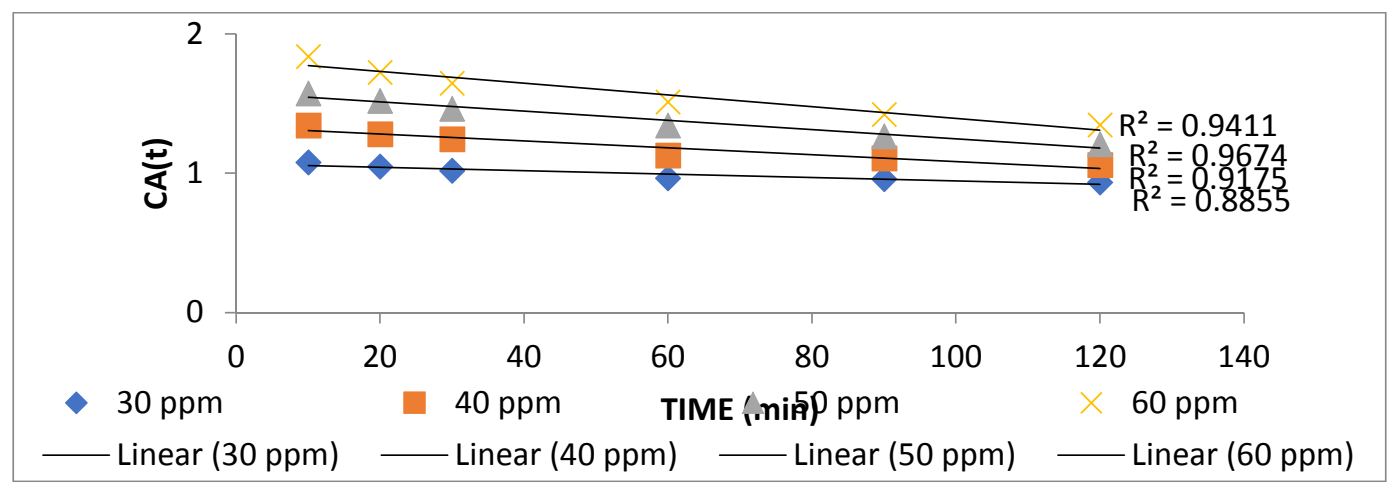

Fig.-8: Graph Showing Time Vs CA (t)

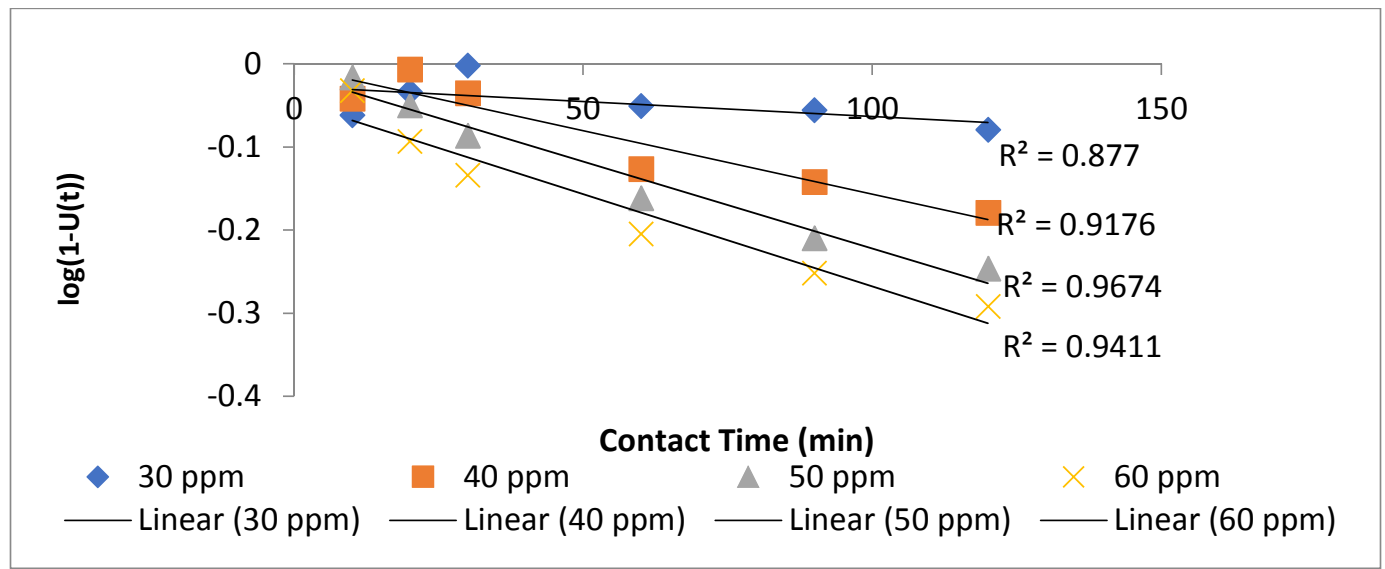

Fig.-9: Graph Showing Contact Time Vs log (1-U(T))

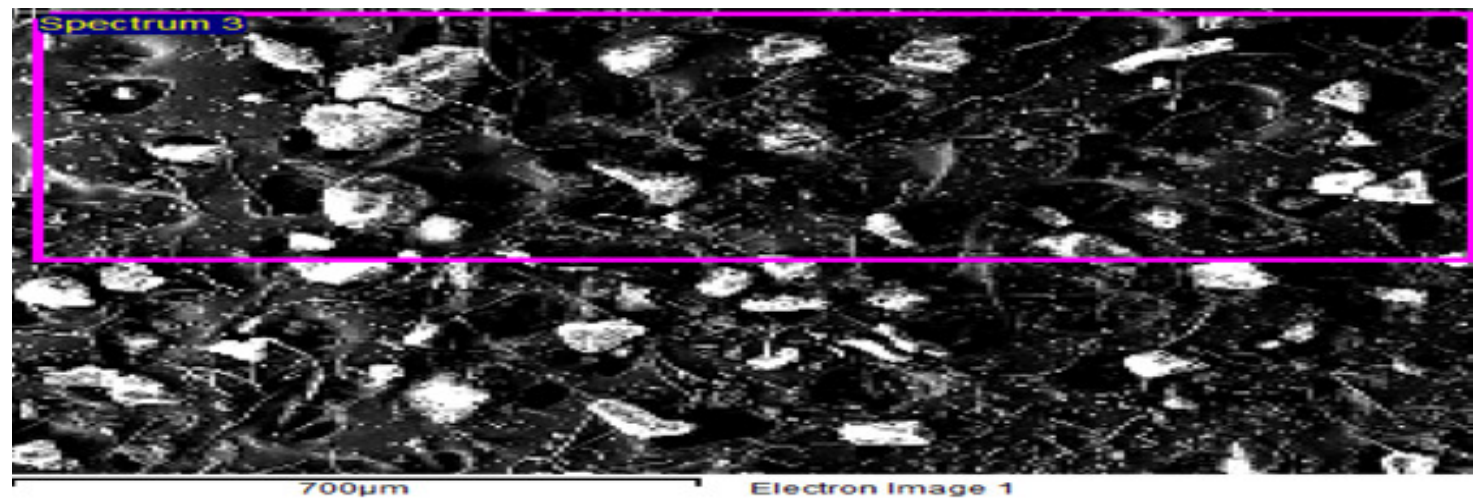

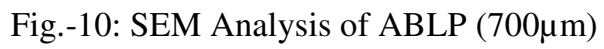

\section{CONCLUSION}

It is concluded that ABLP could be used to remove RY-14dyefromaqueoussolution. The optimum $\mathrm{pH}$ was observed at 2.As the sorbent dose was increased, the percentages of dyes sorbed was also increased and reached maximum value. The adsorption equilibrium was achieved at 4 hours. It was proven that Freundlich isotherm fit well. The adsorption processes followed the pseudo-first-order rate kinetics. When we justify the results shown above we could conclude that Averrhoa bilimbiis an effective dye adsorbent from aqueous solutions. Averrhoa bilimbi leaves-based adsorbent offers many attractive features such as outstanding adsorption capacity for RY-14 dye, low in cost and environmental friendly. It offers 


\section{RASĀYAN J. Chem.}

Vol. 12 | No. 2 |719 - 726| April - June | 2019

significant advantages over currently available adsorbent and in addition, it contributes to agricultural waste minimization strategy.

\section{REFERENCES}

1. M. Luma Ahmed, T. Fatima Tawfeeq, H. Mariam Abed Al-Ameer, Khayal Abed Al-Hussein and R. Afrah Athaab, Scientific Research, 4(11), 34(2016), DOI: 10.4236/gep.2016.411004

2. H. Revathi, A. Kaviyarasu, T. Murugan, M. Dinesh Kumar and R. Sharmila Devi, Rasayan Journal of Chemistry, 11(4), 1415(2018), DOI: 10.31788/RJC.2018.1143054

3. M. Hossen and Imran, Journal of Textile Science \& Engineering, 7(2), 1(2017), DOI:10.4172/21658064.1000293

4. Anitharoy, R.V. Geetha and T. Lakshmi, International Journal of Drug Discovery and Research, 3(3), 101(2011)

5. T. Bhaurav Dangat, A. Anuja Shinde, N. Dipali Jagtap, R. Varsharani Desai, B. Prachi Shinde and V. Rajaram Gurav, Asian Journal of Pharmaceutical and Clinical Research, 7(3), 150(2014)

6. Alisha Valsan and K. Regi Raphael, South Indian Journal Of Biological Sciences, 2(1), 75(2016), DOI:10.22205/sijbs/2016/v2/i1/100347

7. Alhassan Muhammad Alhassan and QamarUdiin Ahmed, Journal of pharmacy and Bioallied sciences, 8(4), 265(2017), DOI:10.4103/0975-7406.199342

8. K.C. Wong and S.N. Wong, Journal of Essential Oil Research, 7(6), 691(2011), DOI: $10.1080 / 10412905.1995 .9700533$

9. Mahalakshmi Mathivanan and S.E. Saranaathan, Rasayan Journal of Chemistry, 11(2), 877(2018), DOI: $10.31788 /$ RJC.2018.1122086

10. K. Velumani, P.E. Kumar and V. Sivakumar, Rasayan Journal of Chemistry, 9(2), 149(2016)

11. Shriya Sharm, Jyotsna Kaushal and Pooja Mahajan, International Journal of advanced technology in Engineering and Science, 4, 143(2016)

12. Hosein Nadia, Mostafa Alizadeha, Morteza Ahmadabadia, C. Ahmad Reza Yarib and Sara Hashemid, Archives of Hygiene Sciences, 1(2), 41(2012)

13. T. Murugan, A. Ganapathy and R. Valliappan, E Journal of chemistry, 7(3), 669(2010), DOI: $10.1155 / 2010 / 127020$

14. Ravi Vital Kandisa, K.V Narayanasaibaba, Khasim Beebi Shaik and R. Gopinath, Journal of Bioremediation and Biodegradation, 7(6), (2016), DOI:10.4172/2155-6199.1000e177

15. M. Rajeswari Kulkarni, T. Revanth, Anirudh Acharya and Prasad Bhat, Resource Efficient Technologies, 3(1), 71(2017), DOI:10.1016/j.refitt.2017.01.009

16. S. Ashish Sartape, M. Aniruddha Mandhare, V. Vikas Jadhav, D. Prakash Raut, A. Mansing Ansue and S. Sanjay Kolekar, Arabian Journal of Chemistry, 10(S3), 229(2017), DOI:10.1016/j.arabjc.2013.12.019

17. P. Pallavi, P. King and Y. Prasanna Kumar, Rasayan Journal of Chemistry, 11(1), 203(2018), DOI: 10.7324/RJC.2018.1111971

18. Parimalam Ramachandran, Raj Vairamuthu and Sivakumar Ponnuswamy, ARPN Journal of Engineering and Applied Sciences, 6(11), 15(2011)

19. H. Revathi, T, Murugan and R. Sharmila Devi, International Journal of Current Engineering and Technology, 7(3), 958(2017).

[RJC-5094/2018] 